\title{
Contaminant Dispersion Within and Around Poultry Houses Using Computational Fluid Dynamics ${ }^{1}$
}

\author{
Sourabh R. Pawar, John M. Cimbala, Eileen F. Wheeler and Darla V. Lindberg \\ The Pennsylvania State University, \\ USA
}

\section{Introduction}

The United States poultry industry is the world's largest producer and exporter of poultry meat. U.S. consumption of poultry meat (broilers, other chicken, and turkey) is considerably higher than either beef or pork, but less than total red meat consumption. The U.S. is also a major egg producer; egg consumption has been reported to be around six eggs per person per week in the country [1]. Poultry producers worldwide depend on sustaining good flock health to remain competitive in both national and international trade. Thousands of chickens are often housed inside a single poultry house, and if one chicken is affected by an airborne virus, then the remaining chickens inside the poultry house have a high chance of getting the disease. This leads to rapid spread of disease within and outside the poultry house and it represents huge economic loss for the producers and companies involved. Therefore, monitoring and control of airborne particles are important issues. The most common diseases are the ones caused by the avian respiratory viruses, including avian influenza, Newcastle disease, Paramyxovirus type 2 and Paramyxovirus type 3 , infectious bronchitis, and infectious laryngotrachitis [2] [3] [4]. These respiratory viruses have been documented to cause major disease outbreaks in poultry. Awareness of potential disease transmission from farms and expectations for proactive responsibility for managing those emissions is under scrutiny by neighbors, regulators, retailers, and environmental interest groups. Measuring and quantifying virus particles is very important from the point of view of control and prevention of epidemic outbreaks. This in turn depends upon understanding the impact of mechanical and biological environments.

Ventilation schemes in poultry houses are used to provide cooling during warm weather and to improve air quality during cold weather. Ventilation thus affects the particle distribution within and emissions from poultry houses. Ventilation air movement can be

\footnotetext{
1 This chapter was written by invitation as an extension to a journal article written by the authors:

Pawar, S. R., Cimbala, J. M. Wheeler, E. F., and Lindberg, D. V. Analysis of Poultry House Ventilation using Computational Fluid Dynamics. Transactions of the ASABE, Vol. 50, Number 4, pp. 1373-1382, September 2007.

Funding from the Penn State Indoor Environment Center is acknowledged.
} 
natural (due to difference in temperature or wind) or forced (due to fans). Natural or forced flow of air through properly sized and managed ventilation openings should continuously replace contaminated air with fresh outside air [5]. Almost all commercial-scale poultry houses use forced ventilation during cold and mild weather, with the majority using fans year-round. This air exchange helps to control relative humidity, reduce dust particles carrying disease pathogens, interrupt the aerobiological transmission pathways, and decrease or dilute the concentration of ammonia and other air pollutants, as well as carbon dioxide. Maintaining a clean and dry environment is essential to reducing molds and associated toxins that contribute to respiratory or digestive problems, which are threats to animal and human health.

Poultry birds are warm-blooded and therefore give off heat. The thermal plume produced by a typical laying hen is visualized with the Schlieren imaging technique in Figure 1. Air currents caused by thermal buoyancy can either enhance or inhibit the forced flow ventilation system, depending on inlet and outlet area and location, height difference between the inlet and outlet, and difference between inside and outside air temperatures [6]. For example, natural air currents may disrupt forced-ventilation air currents at times of relatively low air exchange such as during cold and mild weather. On the other hand, utilizing the "stack effect" (hot air rises) through thermal buoyancy for natural ventilation can provide the primary air exchange needed during some seasons of the year [7] [8]. Thermal buoyancy happens naturally, and the effect of thermal buoyancy can be used to increase the effectiveness of the ventilation system. This is one of the issues considered in this article while proposing a new ventilation system.

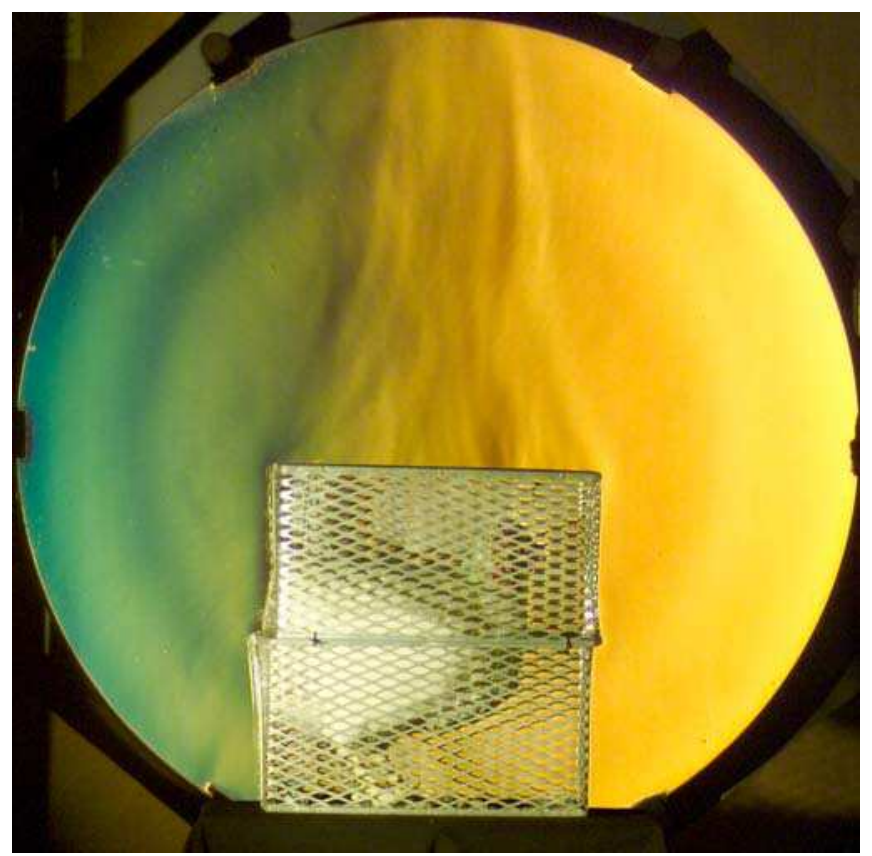

Fig. 1. Schlieren image of a hen in a cage showing the rising thermal plume. Courtesy: Penn State Gas Dynamics Lab. 
Poultry farms fall into two general categories based on the product produced: egg or meat facilities. Meat birds (broilers, turkeys, etc.) are raised on the floor with litter as a manure management material. Most egg-laying hens are housed in stacked cages with the manure dropping through the cage floor. There are two common egg-laying hen house designs, each based on the strategy to manage the manure as a nutrient-rich byproduct. About twothirds of the hen houses in the USA are "high-rise," two-story facilities where the hens are housed upstairs in cages staggered over each other so that manure drops down to the lower story. Accumulated manure is removed once or twice a year as needed for crops. Fresh air is introduced to the facility upstairs to benefit the hens and exhausted downstairs after being used to dry the manure. Most newly constructed hen houses are "manure-belt" houses where a conveyor belt under each cage collects manure for daily or bi-weekly removal from the hen house to a separate storage. With cages stacked directly over each other and both upstairs and downstairs occupied with hens, there can be $50-100 \%$ more hens in a manurebelt house than in the same size high-rise facility. With the adoption of manure-belt cage configuration, the hot weather ventilation usually employs a "wind-tunnel" strategy. Cold and mild weather ventilation is the same in both high-rise and manure-belt houses, albeit with increased ventilation rate in the latter due to the increased number of birds. The present analysis evaluates airflow conditions in relation to the potential for disease spread in a manure-belt house similar to that shown in Figure 2.

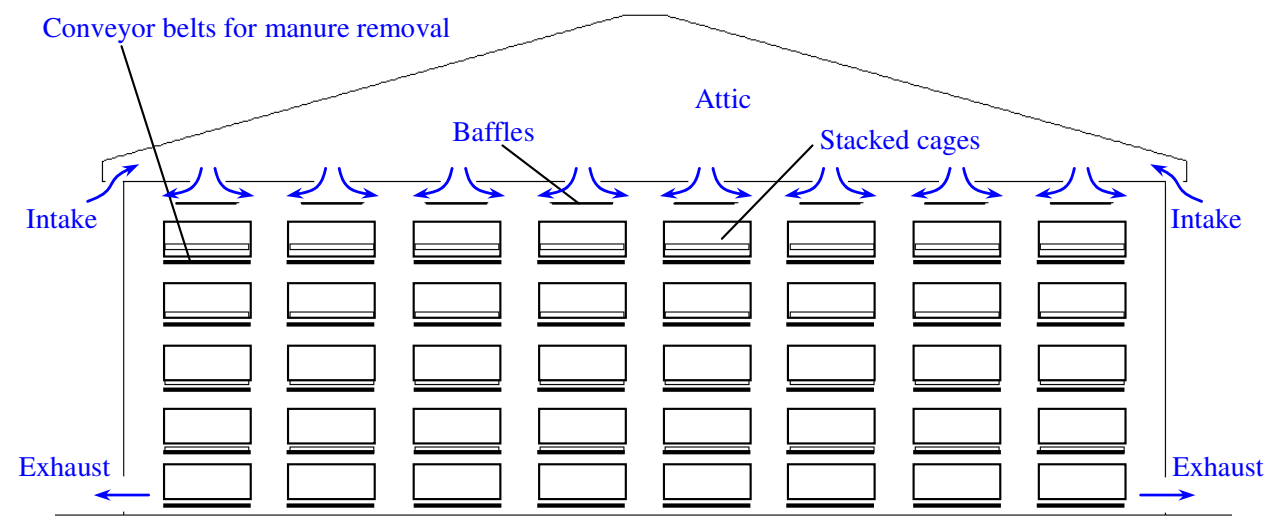

Fig. 2. Cross-sectional slice through a manure-belt equipped hen house with a traditional, downward flow ventilation scheme.

In the event of epidemic outbreak at poultry production facilities, air quality control and decreased contamination spread downwind is of fundamental importance. In this article computational fluid dynamics (CFD) is used to monitor the flow of particles and test the effectiveness of ventilation systems. CFD can be defined as the process of determining a numerical solution to the governing equations of fluid flow while advancing the solution through space and/or time in a computationally modeled domain in order to obtain a numerical description of the flow field of interest. The governing equations can be solved either by writing in-house codes or by using commercial software codes that are designed to give optimum performance and a convenient user interface. In the present research, the commercially available CFD computer software package FLUENT [9] (now part of ANSYS) was used. FLUENT is a three-dimensional finite-volume CFD code, capable of using 
structured, unstructured, and hybrid grids. It can handle both laminar and Reynoldsaveraged turbulent flows, steady and unsteady flows, compressible and incompressible flows, and the transport of contaminant species and particles. To create the geometry and to mesh the computational domain, software accompanying FLUENT called GAMBIT [10] was used. In this work various ventilation scenarios in egg-laying hen houses, in various wind conditions, with both particulate and gaseous contaminants introduced at various locations in the house were studied (a gaseous contaminant introduced at one location is presented here). In particular, a modified ventilation scheme that may reduce the spread of airborne contaminants within the hen house and also to adjacent hen houses was proposed and tested.

Prior to this work, a CFD study of agricultural ventilation characteristics has been reported for greenhouse [11] temperature distributions using FLUENT and of air velocity and ammonia distribution in swine barns [12] and internal climate of broiler houses [13]. Virtual chickens have been included in simulations of internal climate [14].

\section{Geometry and modeling}

The typical hen house in the U.S. is 50-ft wide and 500-ft long, with 16-ft high walls. It has a shallow 4/12 slope on the roof. The hens are housed inside cages which are typically $1.5 \mathrm{ft}$ in depth and $1.2 \mathrm{ft}$ in height. A single, two-story manure-belt hen house may accommodate 150,000 or more birds. There are usually 6 to 8 tiers of cages, stacked on top of each other. The tiers run the entire length of the $500-\mathrm{ft}$ barn. In a poultry facility there are 2 to 8 hen houses arranged side-by-side in a row. There is at least $50 \mathrm{ft}$ of air space between two adjacent houses. This space is required to allow fire truck access and to reduce fire spread. The building separation is also an attempt to have fresh air supply for each house. The reason the separation distance is minimized is to reduce cost of the egg conveying system that connects all houses to the egg handling facility at each farm.

\subsection{Cage, conveyer belt and tier assembly}

The cages that house the hens are of the wire mesh type as shown in Figure 3. The feeding system and the egg conveyor system are attached to the front of the cages. A wide conveyor belt runs under each row of cages to collect manure, which is transported to a separate storage building. In the CFD simulations, the wire mesh cages were modeled as porous walls and the hens inside an individual cage were modeled together as a single block with constant heat flux corresponding to their body temperature. The conveyor belt was modeled as a rectangular wall in between two tiers. The tier system and its model are shown in Figure 4 along with the cage modeling.

\subsection{Ventilation schemes and modeling their components}

Negative pressure ventilation is used in hen housing. Fans discharge air from a tightlyconstructed building envelope that is under a slight negative pressure (vacuum typically 0.05 to 0.10 inches water) so that fresh air enters at planned inlet openings. In this chapter two ventilation schemes are studied and compared with respect to simulated-virus spread and effectiveness in maintaining temperatures uniformly within the building. The first ventilation scheme is the traditional one used in the United States and the second one is the proposed scheme in which the air flow is in a direction exactly opposite to the first one. 


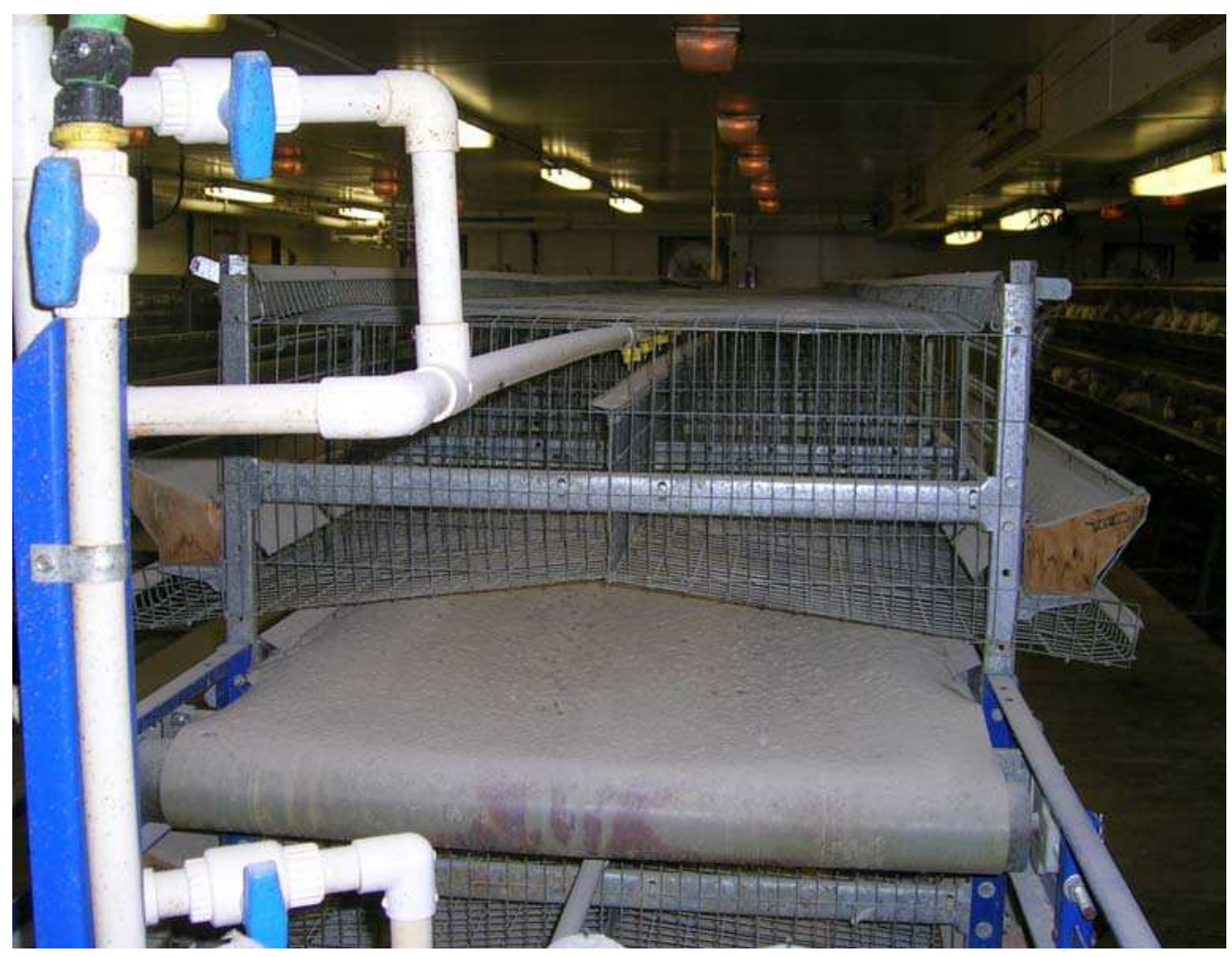

Fig. 3. Cage over manure conveyer belt.

With either ventilation scheme, the volume of air exchange is increased by turning on more fans with the inlet opening size increased to maintain a constant static pressure difference between interior and exterior conditions. When less air exchange is needed, fans are turned off to reduce the volume of air movement through the hen house, and the baffle inlet is closed partially to maintain the constant static pressure difference. In different weather conditions different air flow rates are required; e.g., more flow rate per hen is required in hot weather conditions as compared to cold weather conditions. The same (existing) control system can also be used for the proposed ventilation scheme. There is an automated mechanism that controls the baffle inlet opening according to the temperature-controlled airflow rate inside the hen house. The baffles and their adjustment system are shown in Figure 5.

Of interest is the effect of ventilation on the spread of disease-causing viruses within the hen house and to the neighboring hen houses. The important questions to be answered are: a) If one hen in the house gets infected, how are the other hens affected? b) How does the infection of a hen in one house affect the hens in neighboring houses? These questions remained unanswered until now due to absence of air flow modeling inside and discharge from the poultry houses. 

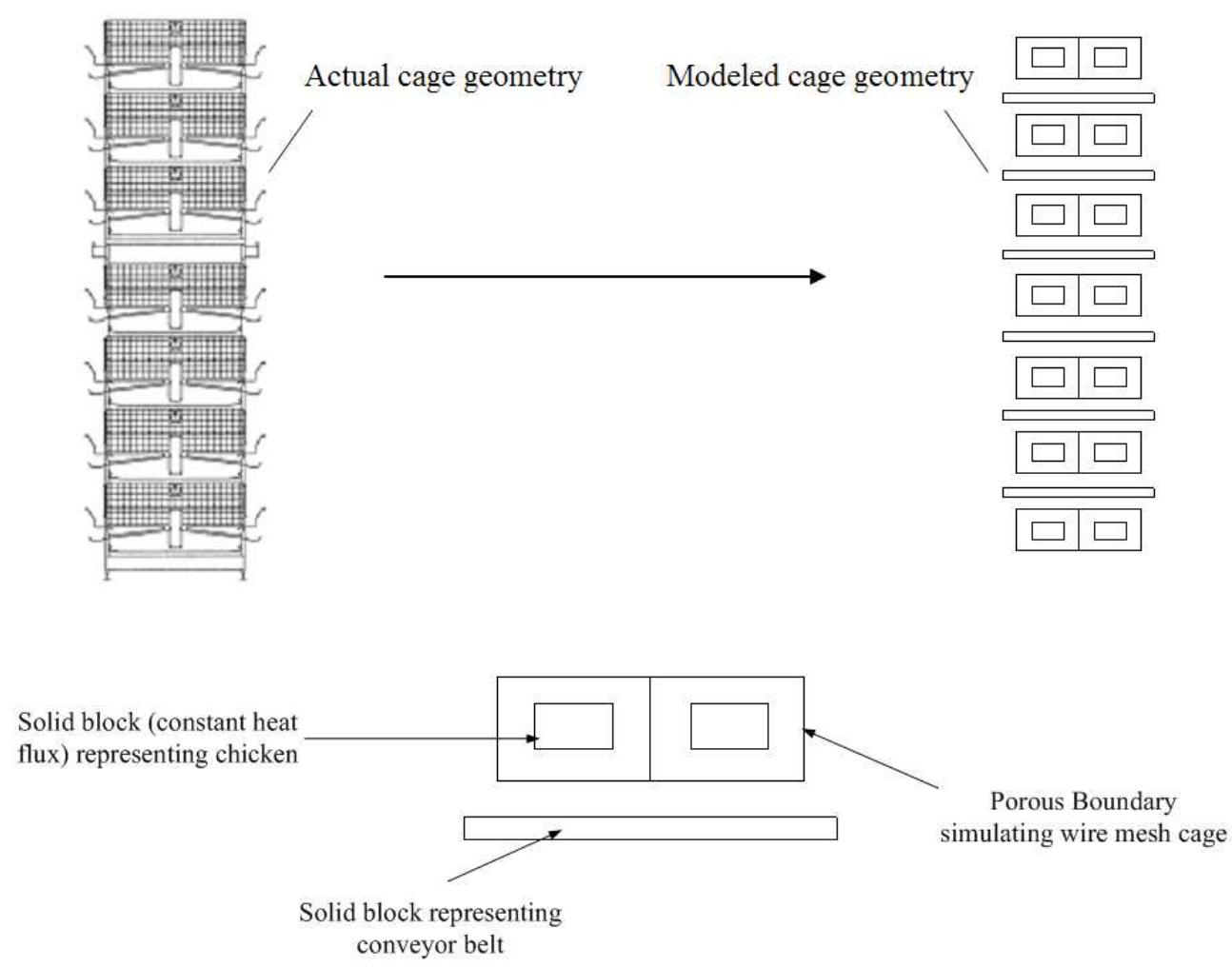

Fig. 4. Cage, conveyer belt and 7-cage tier assembly modeling.

\subsubsection{Traditional ventilation scheme: downward flow}

In this type of ventilation system the air flow is from top to bottom as practiced in high-rise hen houses and manure-belt houses during all but hot weather. Fresh air comes into the attic space at the eaves between the roof and the wall through a 2 to $3 \mathrm{ft}$ continuous opening along the length of the building. Within the attic floor there are slot openings above each cage-row to distribute fresh air uniformly across the upper level of the hen house. Each slot opening has a horizontal baffle to direct incoming air along the ceiling. The air is exhausted outside using fans placed about $3 \mathrm{ft}$ above ground on the lower story of the barn. The ventilation fans are shown in Figure 6. The eave on one side of the poultry house is shown in Figure 7. The problem with this ventilation approach is that the direction of air flow (top to bottom) is against the natural tendency of warm air from the hens to rise, as was shown in Figure 1.

\subsubsection{Proposed ventilation scheme: upward flow}

In this ventilation system the air flow is exactly opposite to that of the previous traditional scheme. In this case the flow comes in from the bottom of the barn and it is vented out using fans placed in the attic, at the top of the roof. This type of ventilation system assists the thermal plume produced by the hens rather than opposing it. It is shown in Figure 8. 


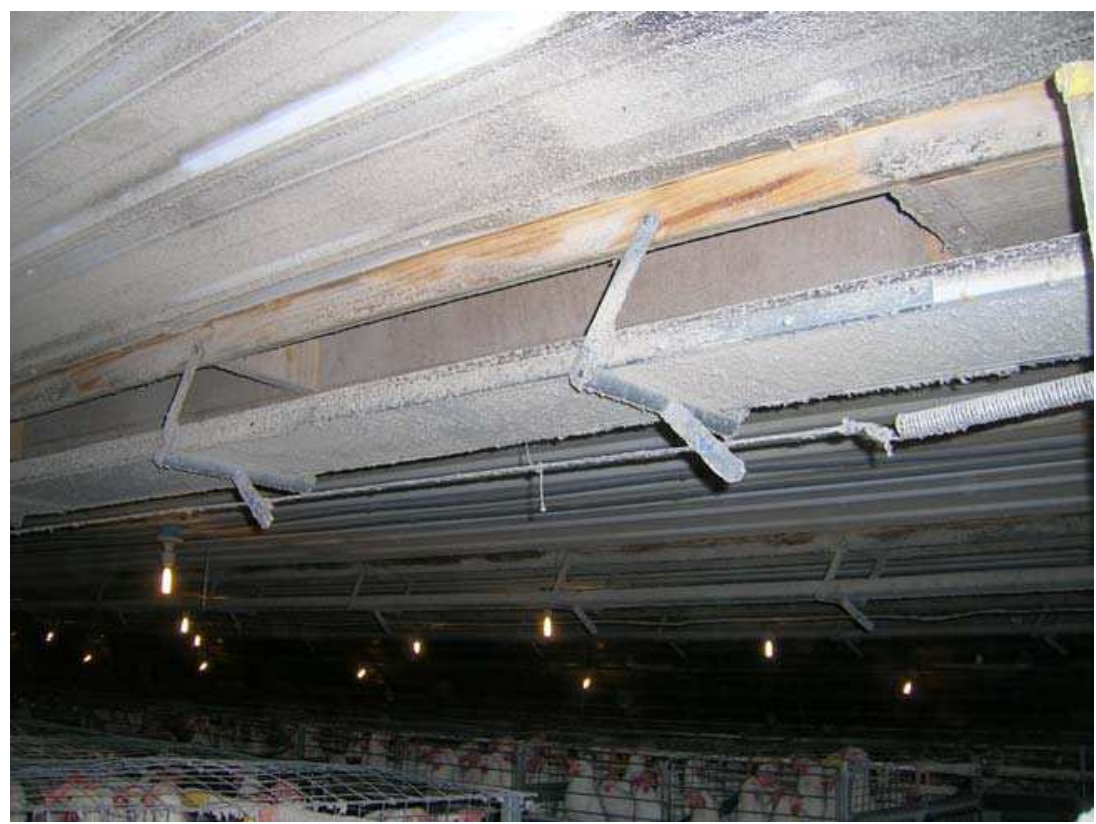

Fig. 5. Horizontal baffle with inlet slot above it is adjustable to match inlet area to air flow capacity of operating fans.

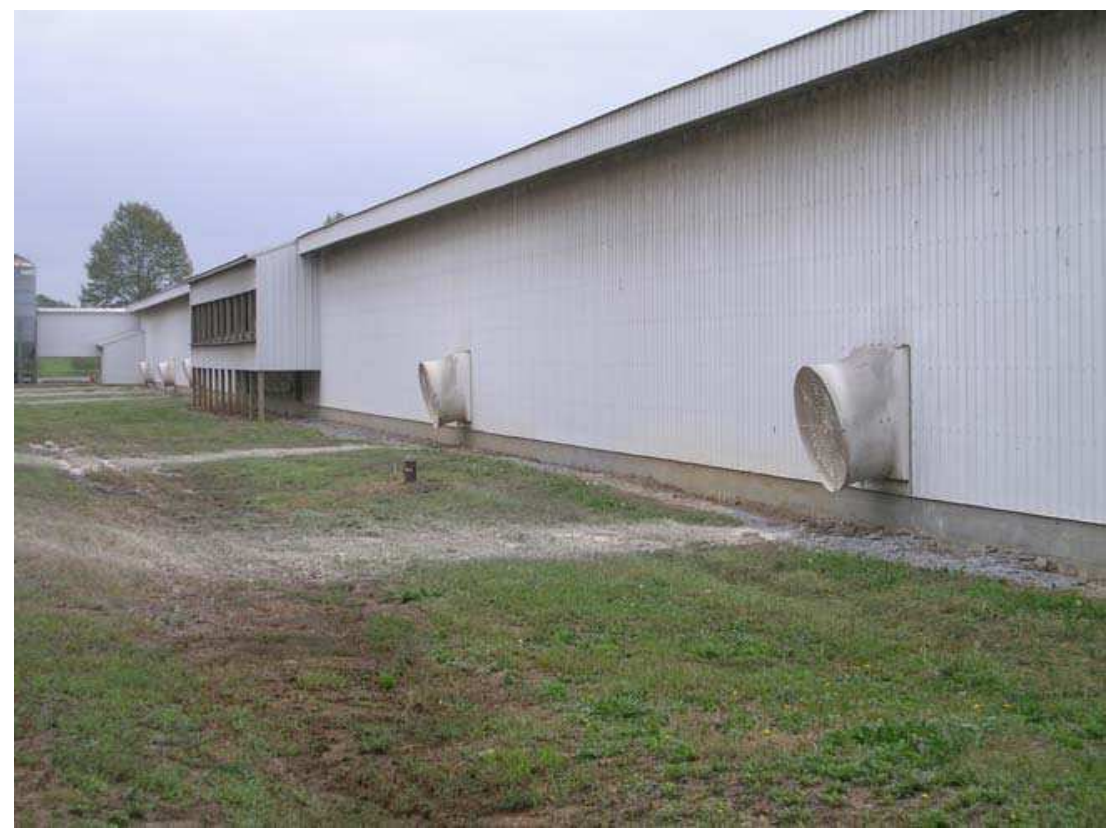

Fig. 6. Fan Arrangement on lower story of hen house. Small extension of building near background has a set of six fans protected to reduce light entry into the building. 


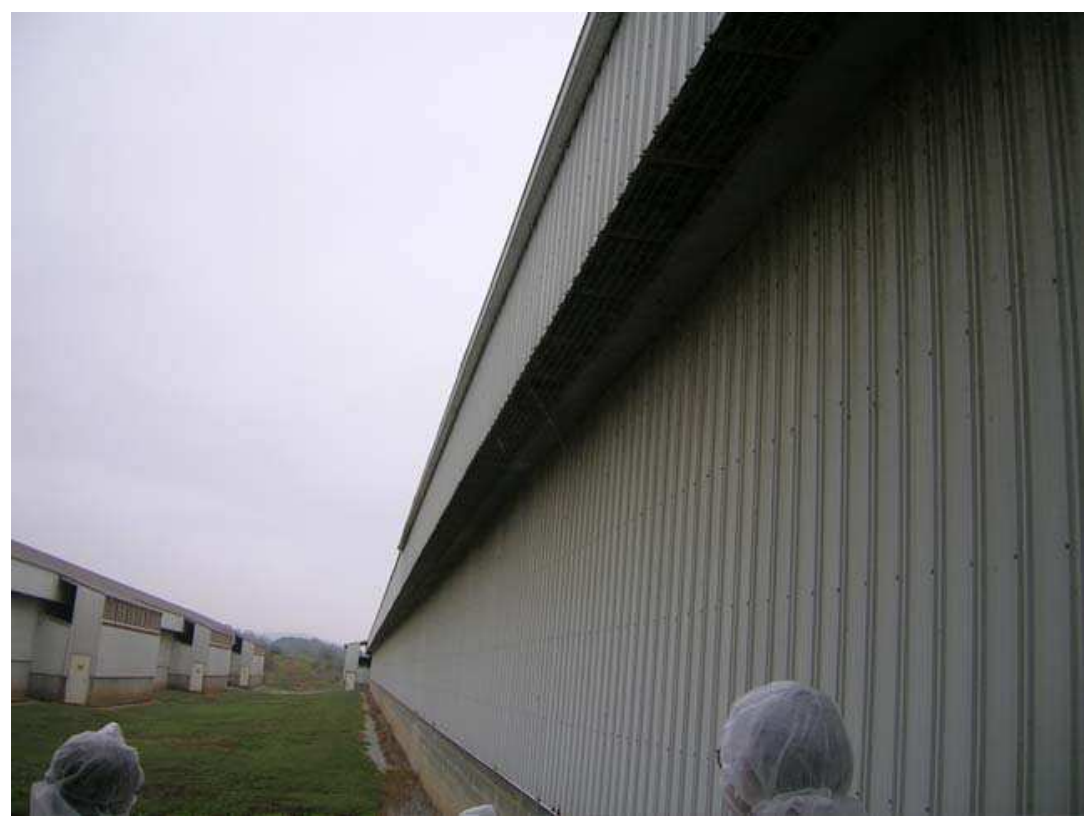

Fig. 7. Open eave along entire length of the poultry house to allow air entry to attic space prior to distribution to building interior.

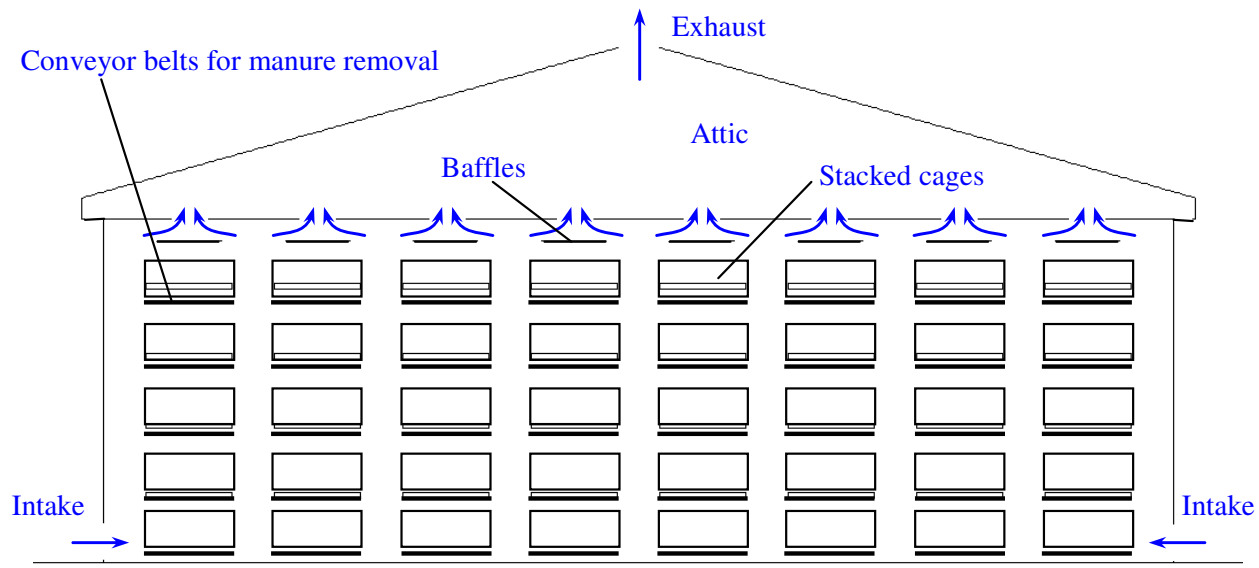

Fig. 8. Proposed ventilation scheme airflow from bottom to top of house.

\subsection{Final 2-D geometry with dimensions}

Incorporating all the above mentioned features, the final 2-D geometry shown in Figure 9 was created and used for the CFD simulation. This geometry was extruded in the third dimension (out of the page in Figure 9) to create the three-dimensional geometry. 

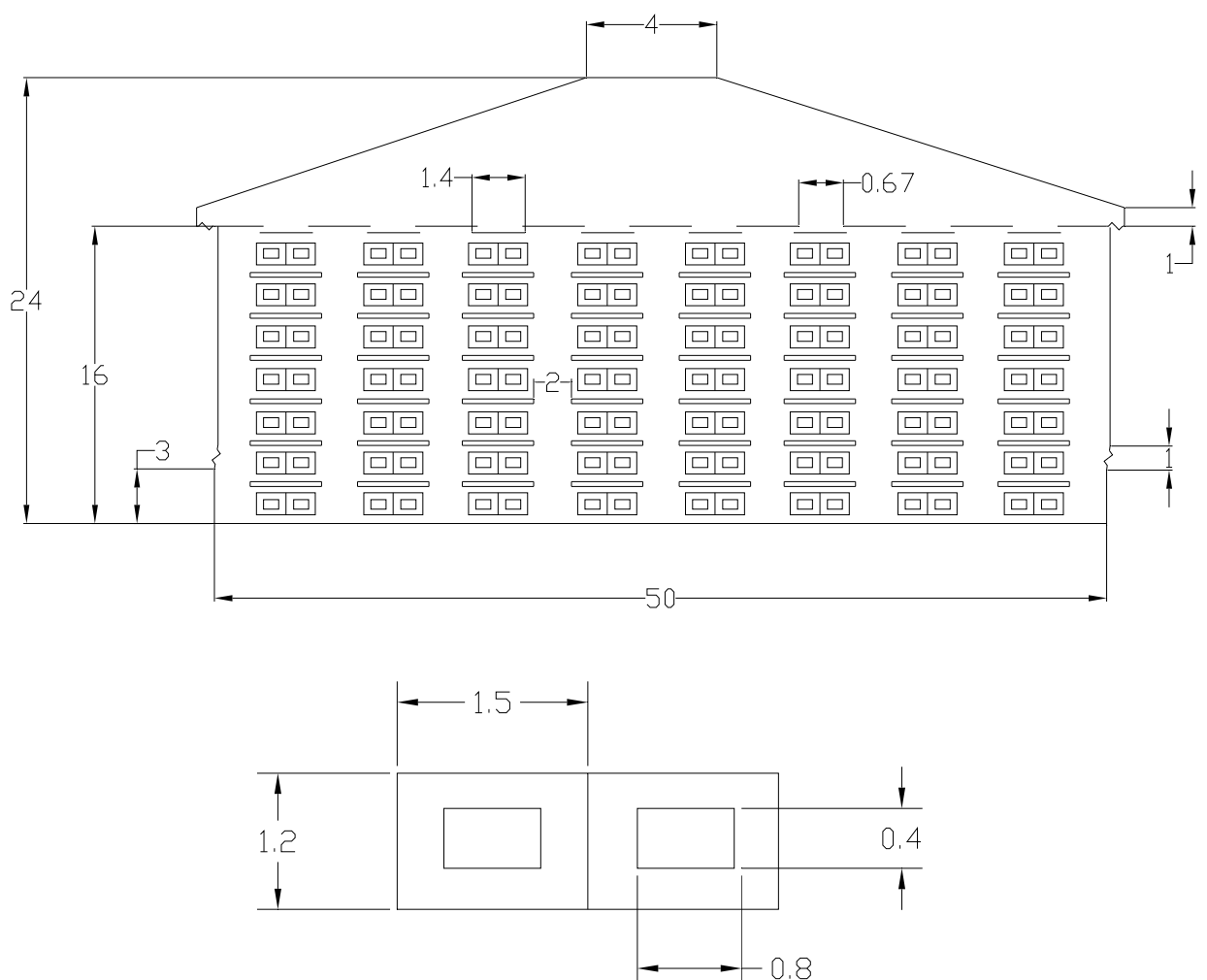

Fig. 9. Two-dimensional simulation model (top) and details of the cages (bottom) with dimensions in feet (cage dimension reference: the Big Dutchman Manual).

\section{Meshing (grid generation)}

In CFD analysis, the geometry (developed in section 2.3) is first enclosed in a computational domain. The size of the domain is determined by various factors. The "approach length" (distance from the start of the domain to the left-most wall of the building) must be sufficiently long so that the inlet flow is sufficiently developed before it reaches the building. The top and right boundaries of the domain are placed such that reverse flow is avoided. In this work only two hen houses are modeled side by side, as in Figure 10, assuming that the flow and thermal interactions would be similar if there were additional barns on the site. The domain extends several barn widths downstream since eddies are created downstream of the buildings. These eddies need to be captured and contained inside the computational domain to avoid reverse flow at the outflow boundary.

The next and the most fundamental consideration in CFD is that of discretization, which involves the process of transforming continuous models and equations into forms suitable for numerical analysis and implementation on a computer. In this case the discretization is initiated by dividing the spatial domain into small cells (finite volumes) to form a volume mesh or grid. Then by using a suitable algorithm/solver, the discretized equations of 


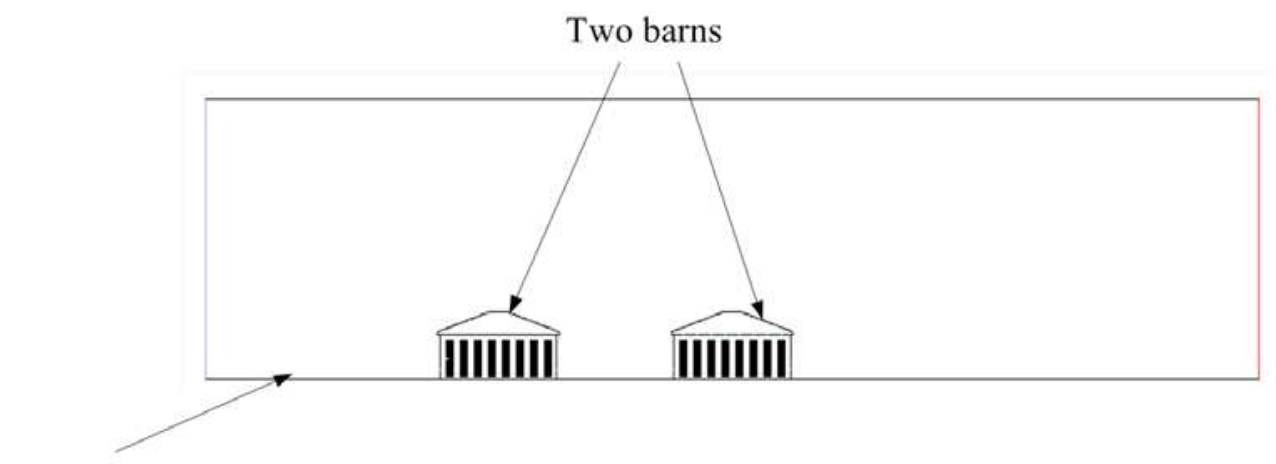

\section{Domain}

Fig. 10. Domain for 2-D mesh.

motion (conservation of mass, energy, and the Navier-Stokes equation of linear momentum) are solved. In FLUENT, the mesh can be regular (quadrilateral cells in 2-D or hexahedral cells in 3-D), irregular (triangular or quadrilateral cells in 2-D or pyramidal volumes in 3-D), or a combination of these (hybrid grid). Information about each cell must be stored separately in memory.

In GAMBIT for the 2-D case, two primary elements are used to mesh faces, namely, quadrilateral and triangular. The quadrilateral elements can be combined with four types of meshes: map, sub map, pave, and tri primitive. Triangular elements can be used only with the pave type. The final result of meshing the domain using the above mentioned elements is shown in Figure 11.

In the mesh for the region of interest, which is the interior of the barn, the grid is fine, i.e., the number of nodes for edges in the interior of the barn is dense. The grid becomes progressively more coarse as focus is shifted away from the barn. This is evident in Figure 11. In 2-D meshes, the quad-map (structured) scheme is usually preferred as it requires fewer cells for a given area and hence less storage space is required.

\section{Boundary conditions}

The next step in CFD analysis is specification of boundary conditions. In the 2-D model the left edge of the domain is a velocity inlet. Velocity inlet boundary conditions are used to define the flow velocity, along with all relevant scalar properties of the flow (such as temperature, turbulence properties, etc.), at flow inlets. The right edge is a pressure outlet where a static (gauge) pressure needs to be specified. The base (ground) and the top part of the domain are walls. The top part of the domain is specified as a zero shear wall. This is done to avoid reverse flow out of the top of the domain and also to keep the height of the domain and thus the number of required grid points as low as possible. This does not significantly affect the flow/thermal characteristics near the barn. The domain with boundary conditions is shown in Figure 12.

The top surface of the roof is a wall for Case 1, the traditional ventilation system (air flow from top to bottom). It is a fan for Case 2, the alternate ventilation system (air flow from bottom to top). The fan boundary condition is a lumped parameter model in which a pressure jump is enforced across the boundary; it is used to determine the impact of a fan 


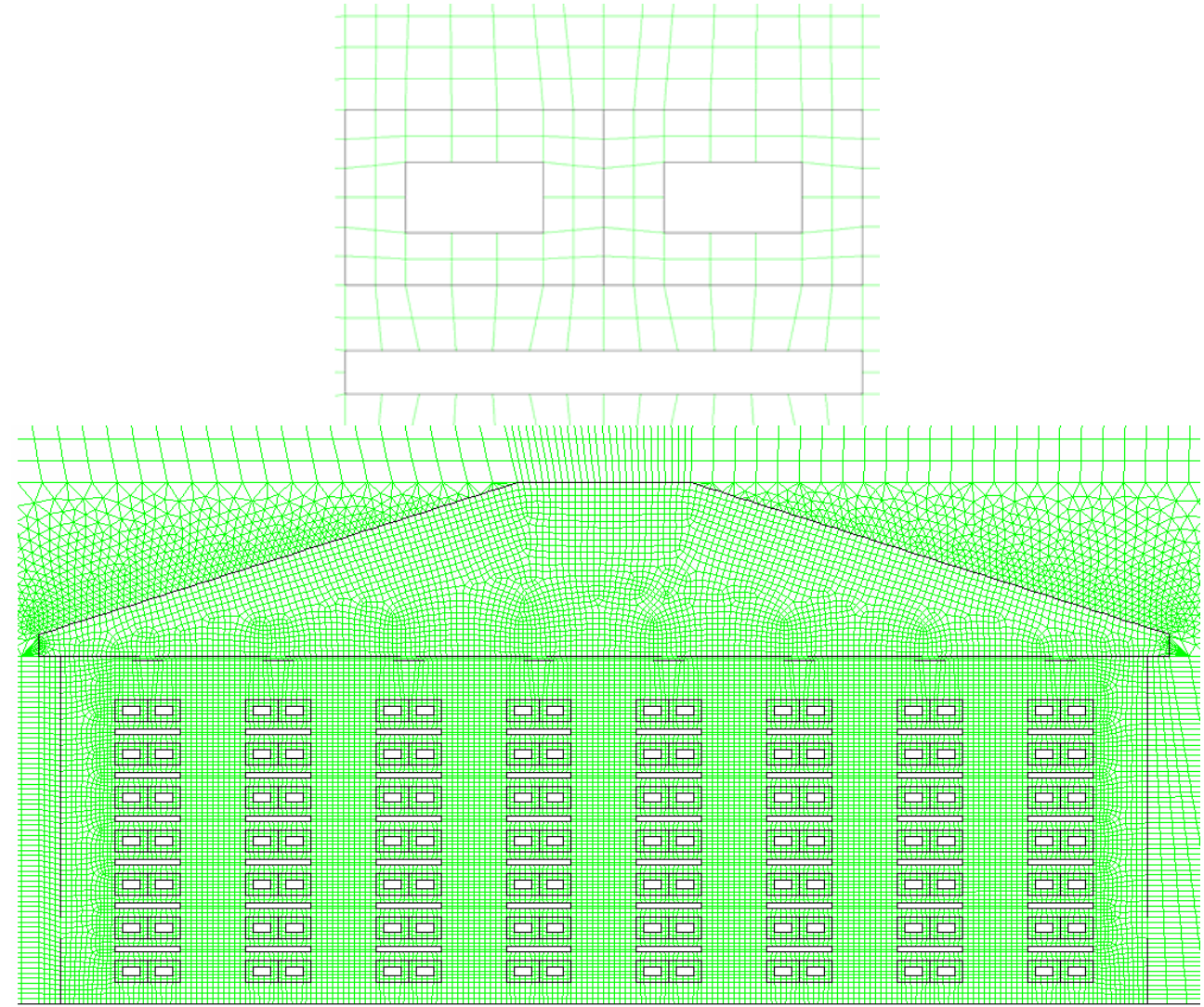

Fig. 11. Details of the 2-D mesh around a cage (top) and in the entire building (bottom).

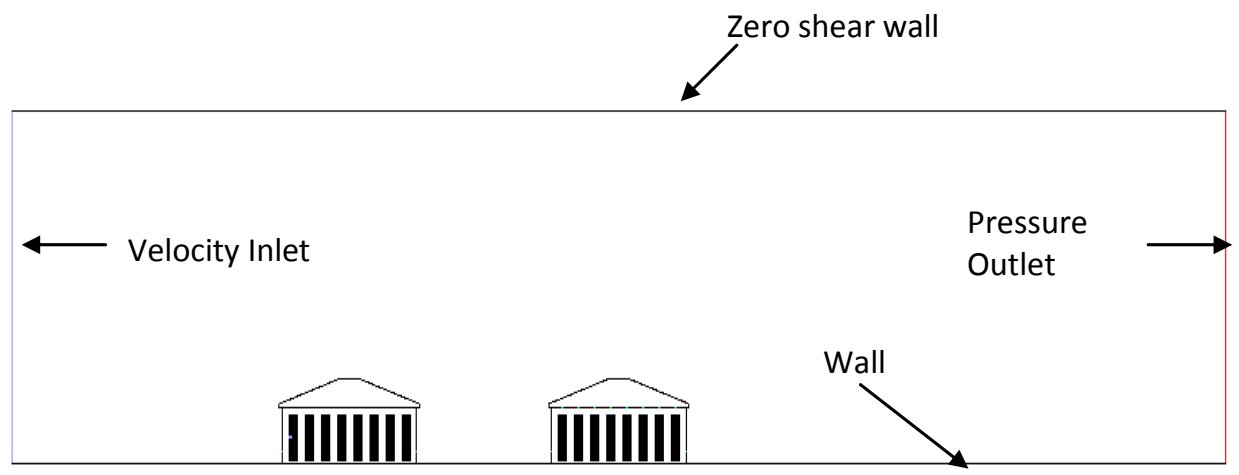

Fig. 12. Boundary conditions for the 2-D computational domain.

with known characteristics upon some larger flow field. The slanting edges of the roof are walls. The eave, the portion projecting out of the side walls of the barn, is an interior face for 
Case 1 and it is a wall for Case 2. This interior boundary is considered as a part of the mesh and the flow is not affected due to it. The slots in the attic space for air are also specified as interior. The baffles are specified as walls. The sides of the barn are walls except for a slot which is a fan for Case 1 and interior for Case 2. The base (floor) of the barn is a wall. The cage is a wire mesh so the boundary condition specified for it is a porous jump. Porous jump conditions are used to model a thin "membrane" that has known velocity/pressure-drop characteristics. The wires used in the mesh are thin, and it is assumed that the cages are $80 \%$ open. Nothing needs to be specified for interior boundary conditions. The solid block representing the hens is a wall. The conveyor belt is a wall. These boundary conditions are summarized in Figure 13.
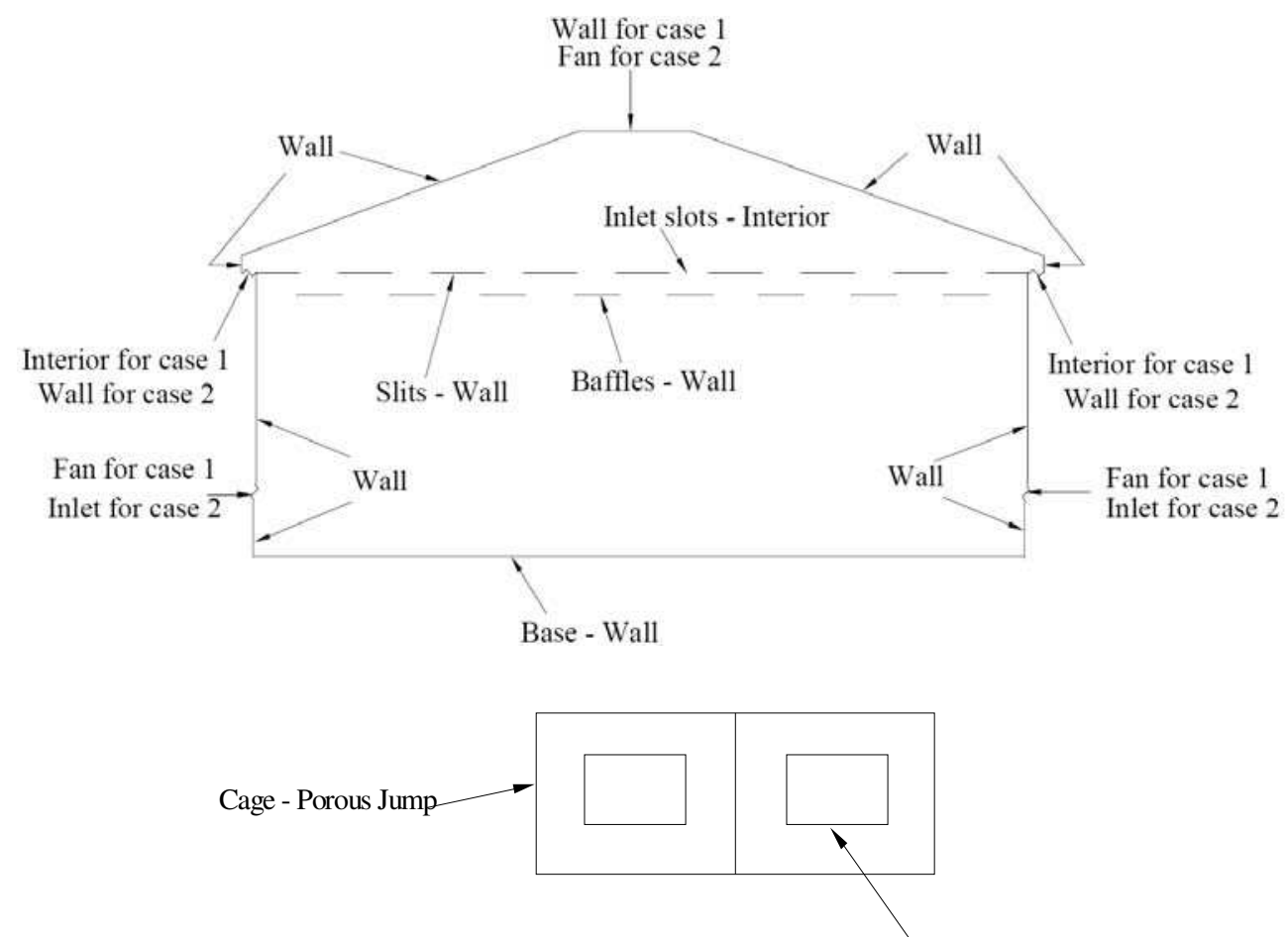

Solid Block representing chickens - Wall

Fig. 13. Boundary conditions for the 2-D poultry house (top) and cage (bottom).

For one particular case to be discussed in detail, the walls are specified as no-slip walls with zero heat flux/constant temperature $(300 \mathrm{~K})$. The blocks representing the hens are no-slip walls with a constant heat flux of $6.577 \mathrm{~W} / \mathrm{m}^{2}$ (calculation shown below). The left edge/face of the domain is specified as a velocity inlet with velocity magnitude of $1.0 \mathrm{~m} / \mathrm{s}$ normal to the boundary, inlet temperature of $300 \mathrm{~K}$, turbulence kinetic energy $(\mathrm{TKE})=0.01 \mathrm{~m}^{2} / \mathrm{s}^{2}$, turbulence dissipation rate (TDR or $\varepsilon$ ) $=0.01 \mathrm{~m}^{2} / \mathrm{s}^{3}$, and a species mass fraction of zero (pure air). The ammonia inlet (analogous to the infected hen) is a velocity inlet condition applied 
to a particular block of hens. The velocity magnitude is $0.010 \mathrm{~m} / \mathrm{s}$ normal to the boundary, the species mass fraction is unity (100\% ammonia), and the rest of the parameters remain the same. The right edge/face of the domain is a pressure outlet. The gauge pressure is zero Pa, backflow total temperature is $300 \mathrm{~K}$, TKE is $0.01 \mathrm{~m}^{2} / \mathrm{s}^{2}$, TDR is $0.01 \mathrm{~m}^{2} / \mathrm{s}^{3}$ and the species mass fraction is zero. For Case 1 two fans per barn (sides of the barn) are specified and for Case 2 only one fan per barn (roof top of the barn) is specified. The pressure difference across the fan is specified as $24.9 \mathrm{~Pa}$ ( 0.10 inch of water column).

\subsection{Calculation of parameters for boundary conditions}

The hens inside the cage, which are represented by a block, are modeled as either a constant heat flux wall or as a constant temperature wall. The constant heat flux boundary condition is preferred since it is more representative.

\subsubsection{Constant heat flux case}

The basal metabolic rate for warm blooded animals like chickens can be approximated by the following empirical equation,

$$
\dot{M}_{b} \text { (in watts) }=3.39\left(m_{b}^{0.75}\right)
$$

where $m_{b}$ is the animal body mass in $\mathrm{kg}$. For example, a typical hen has a mass of $m_{b}=3.0$ lbm $(1.36 \mathrm{~kg})$, and thus $\dot{M}_{b}=4.28 \mathrm{~W}$. If there are 8 hens per cage, the heat generated per cage is $34.2 \mathrm{~W}$. For unit depth the heat flux is given by

$$
\text { Heat flux }=\frac{\text { Total heat generated }}{\text { perimeter } \times 1 \mathrm{~m}}
$$

where the perimeter is $5.2 \mathrm{~m}$ in the present case. Thus, the heat flux is calculated to be 6.58 $\mathrm{W} / \mathrm{m}^{2}$.

\subsubsection{Constant temperature case}

Two hen body temperatures were considered in the modeling, depending on the conditions of the outside air temperature:

a. Mild and cold atmospheric conditions: Hen skin temperature set to $68^{\circ} \mathrm{F}$.

b. Hot atmospheric conditions (outdoor temperature above $70^{\circ} \mathrm{F}$ ): Hen skin temperature set to ambient temperature $+5^{\circ} \mathrm{F}$

\subsubsection{Baffle openings for mild atmospheric conditions}

The required air flow rate in the hen house was calculated as follows:

$$
\begin{aligned}
\text { Required air flow rate } & =(\text { flow rate per } \mathrm{lbf}) \\
& \times(\text { weight of one chicken }) \\
& \times(\text { number of chickens in the barn })
\end{aligned}
$$

For the mild conditions studied in detail here, the flow rate per pound was taken to be 1.0 cubic feet per minute (CFM) per lbf, the weight of one hen was estimated as $3.0 \mathrm{lbf}$, and the 
number of hens in the barn was 158,000. Thus, the required air flow rate was 474,000 CFM. At the inlet (at the attic floor, which is also the hen house ceiling), the standard design is to provide $1.7 \mathrm{ft}^{2}$ of inlet area per 1000 CFM of fan capacity. So the required inlet area for 474,000 CFM was $805.8 \mathrm{ft}^{2}$. This area was divided between eight inlets in the attic. Thus, the required area per inlet was approximately $100 \mathrm{ft}^{2}$. Since the length of the barn was $500 \mathrm{ft}$, the baffle opening was set to $0.20 \mathrm{ft}$. The static pressure difference across the fan was set to 0.10 inches of water column (24.9 Pa).

\subsubsection{Pressure drop across the wire mesh cage}

Instead of meshing the cages (which would require an extremely fine computational mesh), a porous jump boundary condition was applied in the CFD model in place of the cages. The pressure drop across a wire mesh or screen is calculated as

$$
\Delta p=K_{L}\left(\frac{1}{2} \rho V_{2}^{2}\right)
$$

where $K_{L}$ is the loss factor, $\rho$ is the density of the air, taken to be $1.25 \mathrm{~kg} / \mathrm{m}^{3}$, and $V_{2}$ is the velocity of the air through the open area of the mesh. However, the loss factor needs to be estimated. The velocity through the mesh is calculated as follows, using Figure 14 as a guide:

$$
V_{2}=V_{1} \times \frac{A_{1}}{A_{2}}=\frac{s}{s-d}
$$

where $V_{1}$ is the air velocity before the mesh. To determine the pressure drop, the Bernoulli equation (ignoring elevation differences) is applied,

$$
\frac{p_{1}}{\rho g}+\frac{V_{1}^{2}}{2 g}=\frac{p_{2}}{\rho g}+\frac{V_{2}^{2}}{2 g}
$$

or,

$$
\Delta p=p_{1}-p_{2}=\frac{\rho}{2}\left(V_{2}^{2}-V_{1}^{2}\right)
$$

Once the pressure drop is estimated, the loss factor is calculated from Equation 4. FLUENT uses an adjusted loss factor which is calculated as

$$
K_{L}^{\prime}=K_{L} \times \frac{V_{2}^{2}}{V_{1}^{2}}
$$

Finally, the pressure jump coefficient is given by

$$
C_{2}=\frac{K_{L}^{\prime}}{\text { thickness }}
$$

where the thickness in the denominator of Equation (9) is the thickness of wire in the wire mesh - the thickness across the porous jump. For the particular case discussed here, $C_{2}=$ 
201.2 per meter. FLUENT's default value of face permeability $\left(1.0 \times 10^{10} \mathrm{~m}^{2}\right)$ was used, and the porous medium thickness was specified as $1.0 \mathrm{~mm}$.

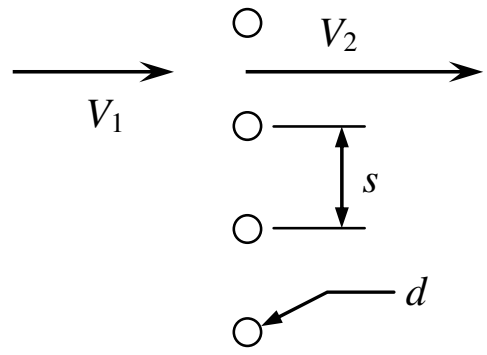

Fig. 14. Simplification of the cage wire mesh, used to calculate porous jump parameters.

\section{CFD setup and results}

For the results reported here, the CFD solver FLUENT was set up to run in 2-D double precision mode. We also ran three-dimensional cases, not shown here, with similar results [15]. The mesh was imported from the grid generator GAMBIT. The segregated solver was used. The $k-\varepsilon$ model was used for turbulence; the constants used are given in Table 1.

\begin{tabular}{|c|c|}
\hline$C_{2, \varepsilon}$ & 1.9 \\
\hline TKE Prandtl number & 1 \\
\hline TDR Prandtl number & 1.2 \\
\hline Energy Prandtl number & 0.85 \\
\hline Wall Prandtl number & 0.85 \\
\hline Turbulent Schmidt number & 0.7 \\
\hline
\end{tabular}

\section{Table 1. Constants used in FLUENT}

For simulating the spread of airborne virus an air/ammonia mixture was used. The thermal conductivity of the mixture was specified to be $0.025 \mathrm{~W} / \mathrm{m}-\mathrm{K}$ and the viscosity was $1.72 \times$ $10^{-5} \mathrm{~kg} / \mathrm{m}$-s. The mass diffusivity was $2.88 \times 10^{-5} \mathrm{~m}^{2} / \mathrm{s}$. The density was calculated using the ideal gas law, and the specific heat was calculated using the mixing law. The species model was enabled without volumetric reactions. The under-relaxation factors and discretization methods are summarized in Tables 2 and 3.

The operating conditions were then specified. The operating pressure was set to $101,325 \mathrm{~Pa}$ and the operating temperature was set to $288.16 \mathrm{~K}$. Also, gravity was enabled and the gravitational acceleration was specified as $9.81 \mathrm{~m} / \mathrm{s}^{2}$ in the negative $y$-direction (down). The boundary conditions were specified using the parameters calculated above. The flow field was initialized using the values listed in Table 4. 


\begin{tabular}{|c|c|}
\hline Variable & Under-relaxation factor \\
\hline Pressure & 0.15 \\
\hline Density & 1 \\
\hline Body forces & 1 \\
\hline Momentum & 0.35 \\
\hline Turbulence kinetic energy & 0.4 \\
\hline Turbulence dissipation rate (TDR) & 0.4 \\
\hline Turbulent viscosity & 1 \\
\hline Species & 1 \\
\hline Energy & 1 \\
\hline
\end{tabular}

Table 2. Under-relaxation factors

\begin{tabular}{|c|c|}
\hline Variable & Method \\
\hline Pressure & Standard \\
\hline Density & Second-order upwind \\
\hline Momentum & Second-order upwind \\
\hline TKE & Second-order upwind \\
\hline TDR & Second-order upwind \\
\hline Species & Second-order upwind \\
\hline Energy & Second-order upwind \\
\hline
\end{tabular}

Table 3. Discretization methods

\begin{tabular}{|c|c|}
\hline Variable & Initialized value \\
\hline Gauge pressure & $0 \mathrm{~Pa}$ \\
\hline$x$ velocity component & $0 \mathrm{~m} / \mathrm{s}$ \\
\hline$y$ velocity component & $0 \mathrm{~m} / \mathrm{s}$ \\
\hline TKE & $0.01 \mathrm{~m}^{2} / \mathrm{s}^{2}$ \\
\hline $\mathrm{TDR}$ & $0.01 \mathrm{~m}^{2} / \mathrm{s}^{3}$ \\
\hline $\mathrm{NH}_{3}$ & 0 \\
\hline Temperature & $300 \mathrm{~K}$ \\
\hline
\end{tabular}

Table 4. Flow-field initialization values

The iteration procedure was then started. The FLUENT solution was allowed to converge, i.e., the residuals decrease below the convergence criteria set for them. After this, postprocessing was performed. In particular, contour plots and vector plots of several variables were generated. For the case of particulate contaminants (not presented here), the particle 
injection/tracking capability of FLUENT was utilized, whereby particle paths are tracked using a Runge-Kutta scheme after the particles are injected from specified surfaces. For gaseous contaminants, FLUENT has multiple species capability, and mass fraction contour plots are readily generated.

As an example of gaseous contaminant diffusion, Figure 15 shows a comparison of ammonia mass fraction contours for both ventilation schemes. The hen in the fourth cage in the first (left-most) column of the first (upstream) poultry house was considered to be affected by a disease. The scale of this contour plot is clipped at a mass fraction of 0.1. The figure shows the spread of contaminant for both cases and the amount of contaminant that passes out of the upstream barn and enters into the downstream barn. Figure 16 shows diffusion contours inside the upstream barn. The white region is a region with very high concentration of contaminant (off the scale). Figure 17 shows the diffusion contours inside the downstream barn. This illustrates spread of contaminant from the upstream barn to the downstream one.

Figure 18 shows a comparison of temperature contours for the two cases. The air enters at ambient temperature and the temperature variations are caused by the body heat given off by the hens. Figure 19 shows temperature variations inside the upstream poultry house, which is an indicator of ventilation system performance. The temperature values are in Kelvin (K).

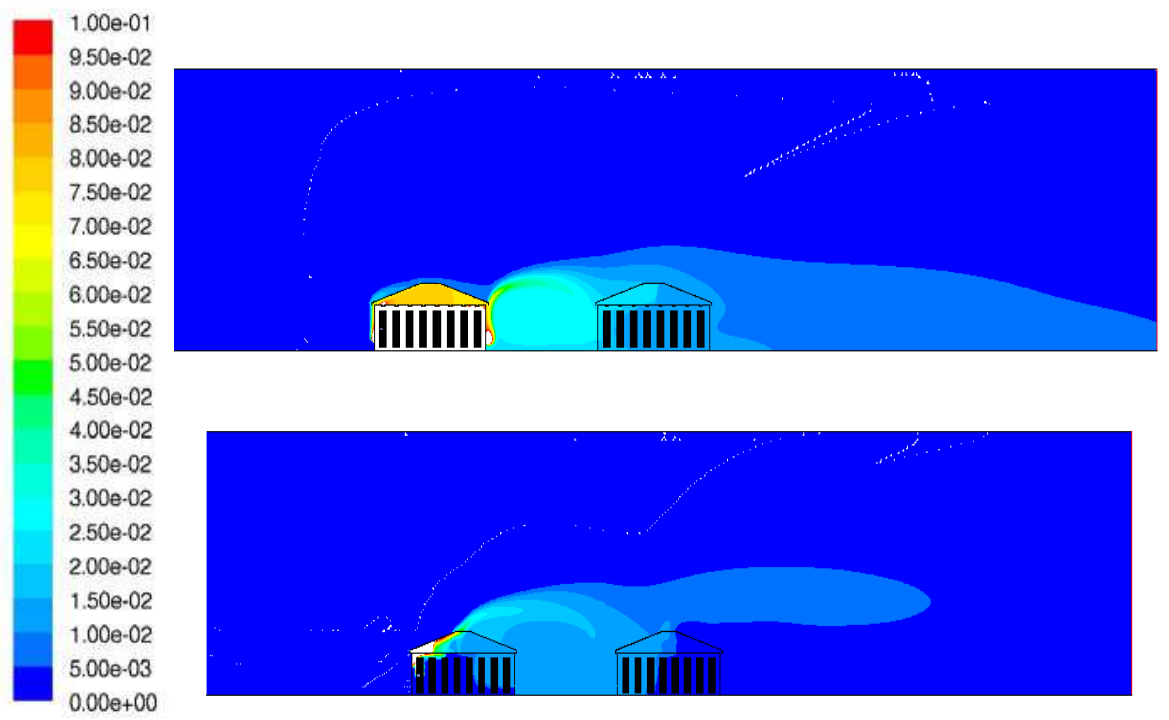

Fig. 15. Comparison of species diffusion contours inside the domain for Case 1 (downward flow) in the top image and Case 2 (upward flow) in the bottom image. 

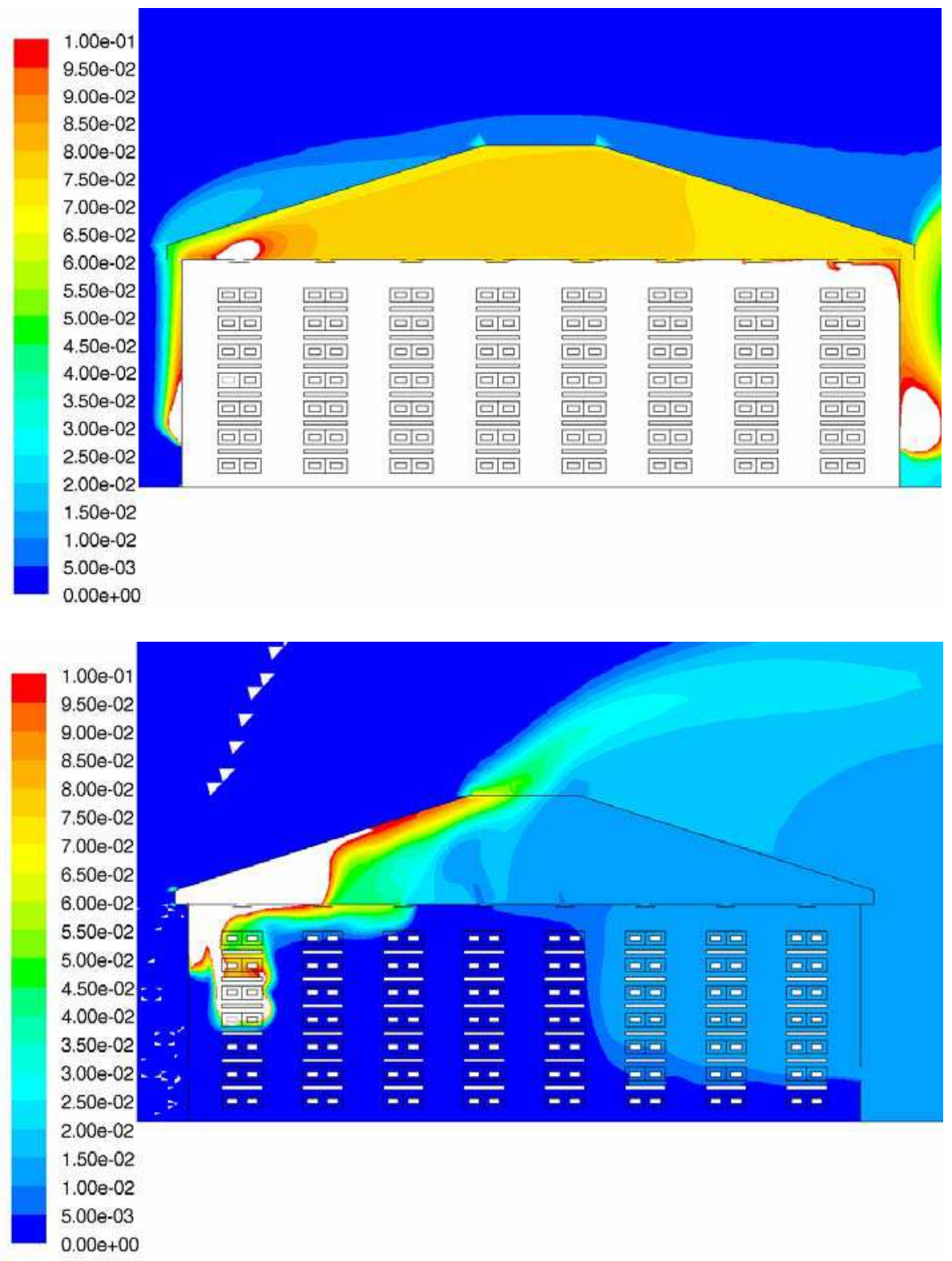

Fig. 16. Comparison of species diffusion contours inside the upstream poultry house for Case 1 (downward flow) in the top image and Case 2 (upward flow) in the bottom image. 

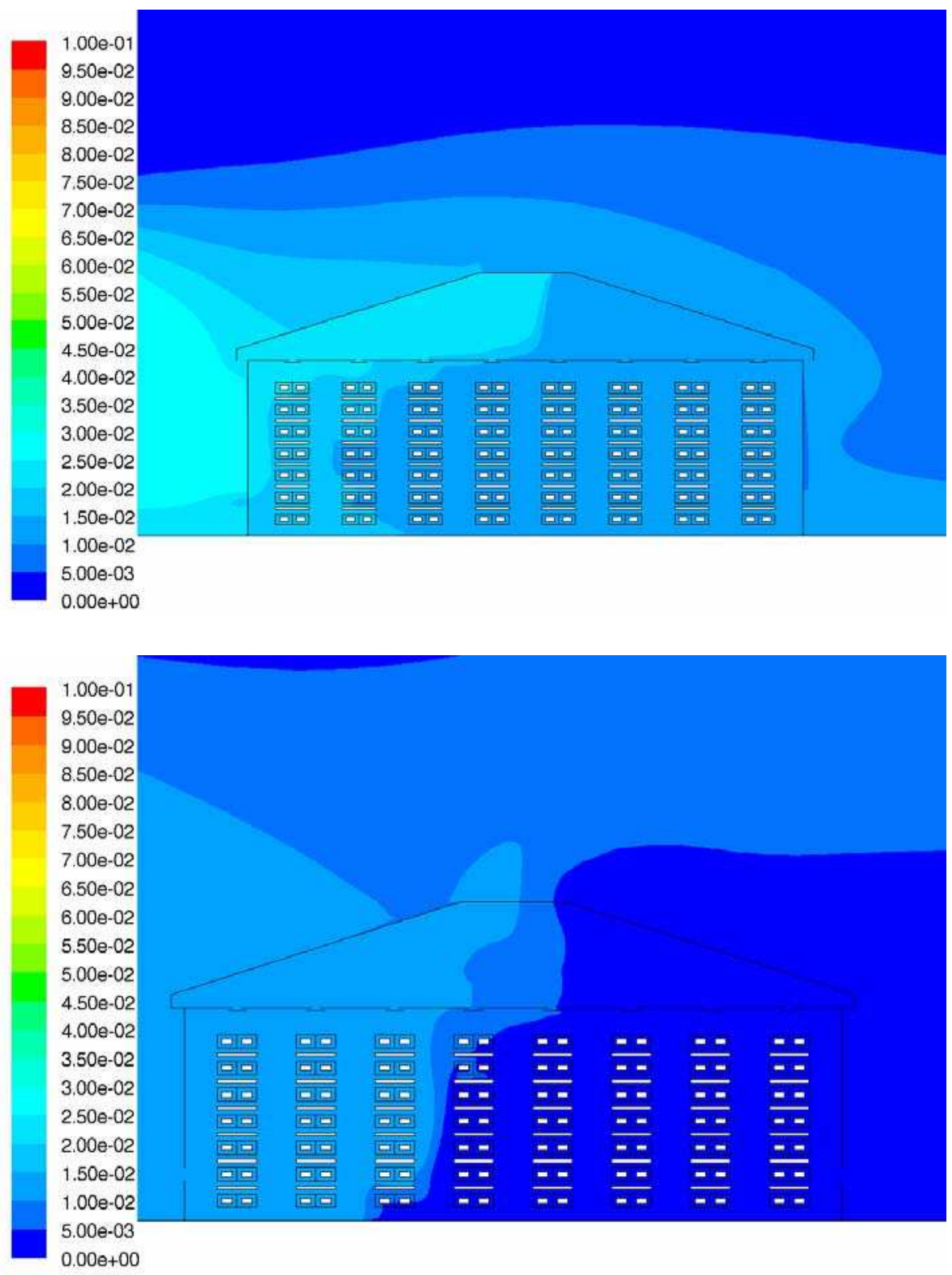

Fig. 17. Comparison of species diffusion contours inside the downstream poultry house for Case 1 (downward flow) in the top image and Case 2 (upward flow) in the bottom image. 


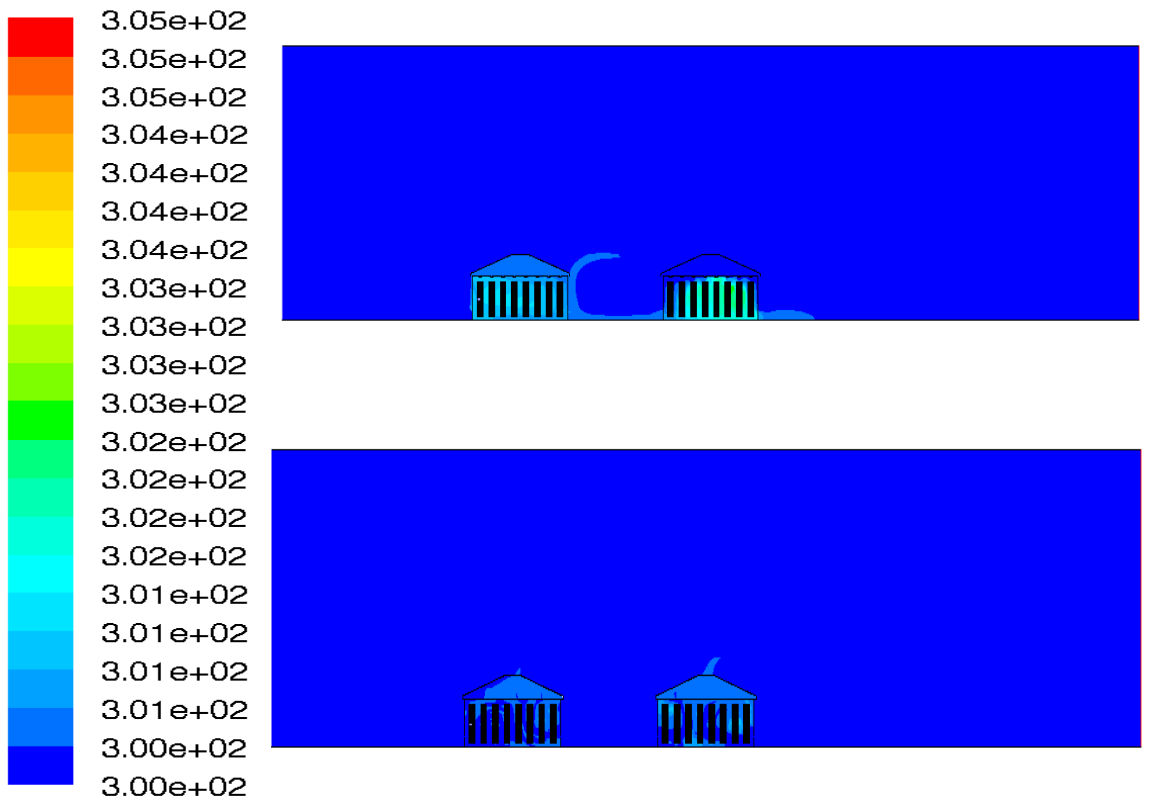

Fig. 18. Comparison of temperature contours in the entire computational domain for Case 1 (downward flow) in the top image and Case 2 (upward flow) in the bottom image.

\section{Observations, conclusions, and future scope}

The main objective of this article was to compare the two ventilation schemes from the view point of air quality and ventilation characteristics. Therefore, only species diffusion contours and temperature contours were analyzed. Species diffusion contours are good indicators for performance of ventilation schemes from the view point of air quality. It has been assumed that the hen in cage 4 of the first row of the upstream poultry house has been affected by a disease, i.e., the contaminant is injected from this cage. For the species diffusion contours the scale has been clipped to a range of 0-0.1 mass fraction. The white region indicates high concentrations of the contaminant. The contaminant coming out of the upstream poultry house affects the downstream poultry house much more in downward flow (Case 1) than in upward flow (Case 2) as shown in Figures 15, 16, and 17. This is primarily due to fan position in both cases. The outlets of fans for downward flow oppose each other and due to this the air exhausted outside through the outlet of the upstream poultry house rises and enters the inlet of the adjacent poultry house. In upward flow the fans are placed on the roof so that the exhaust air is ejected directly up and above the adjacent poultry houses and does 

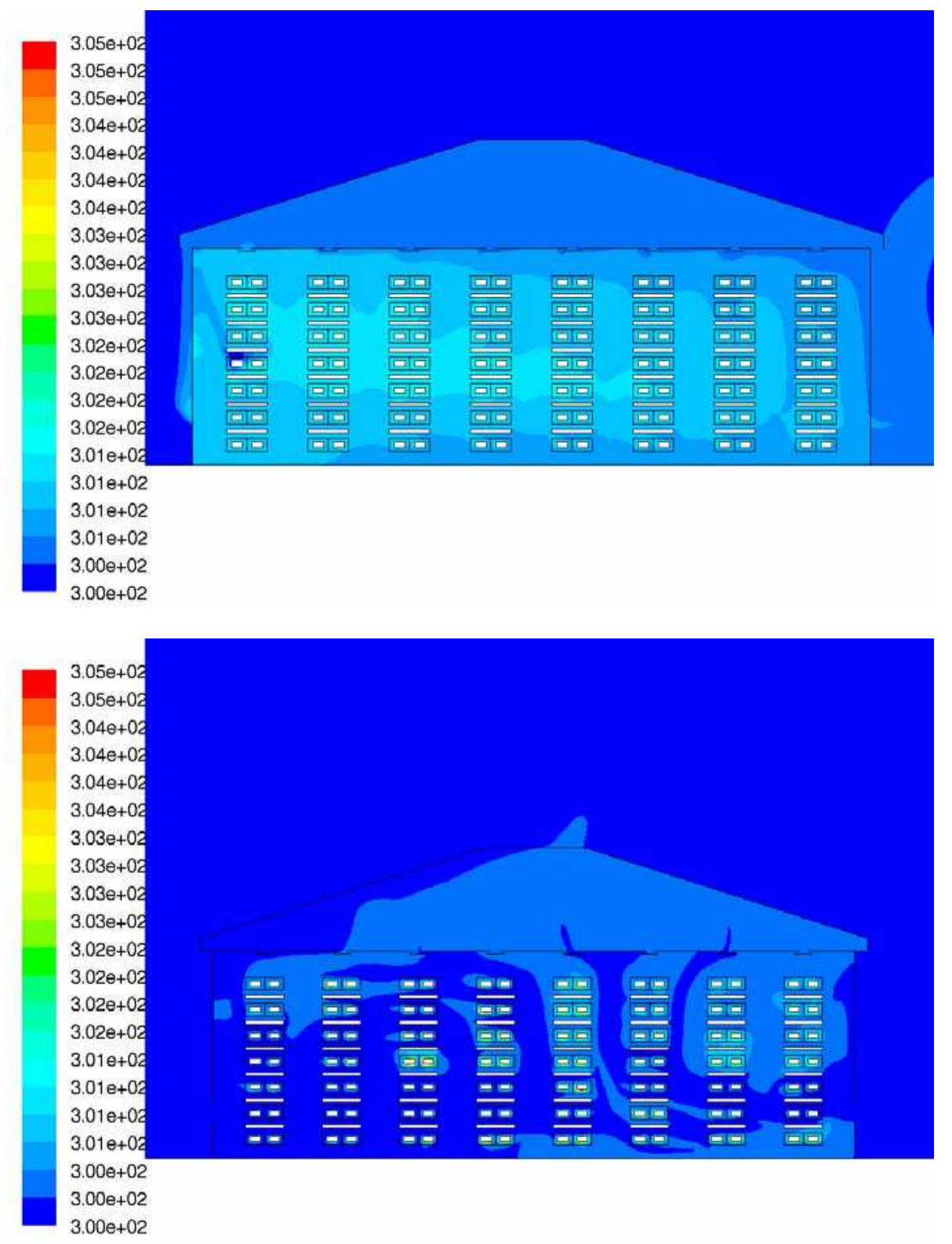

Contours of Static Temperature $(k)$

Mar 18, 2006 FLUENT 6.2 (2d, dp, segregated, spe, rke)

Fig. 19. Comparison of temperature contours inside the upstream poultry house for Case 1 (downward flow) in the top image and Case 2 (upward flow) in the bottom image. 
not interfere significantly with the inlets of the downstream poultry houses. (The minimal amount of species diffusing from poultry house 1 to poultry house 2 in Case 2 results partly from the domain height being limited in FLUENT.) Due to this, the contaminant spread from the upstream poultry house to the downstream one is much less with upward flow than with downward flow. Inside the upstream poultry house it is also observed that contaminant diffusion is much less for upward flow as compared to downward flow. In Figure 16 it is observed that for downward flow the entire interior of the poultry house is colored white which indicates high concentration of contaminant inside the poultry house. In upward flow the diffusion of the contaminant inside the poultry house is restricted to a few regions and the concentration of the contaminant in these regions is low. This is because the rising warm plume of air in Case 2 naturally flows upward, carrying the contaminant with it and out the exhaust. In Case 1, however, the air flow tends to diffuse the contaminant inside the poultry house because the direction of flow is opposite to the natural thermal plumes from the hens.

Comparison of the temperature contours for both ventilation schemes in Figures 18 and 19 shows that the ventilation system in upward flow is more effective than that in downward flow. The temperature contours in downward flow are predominantly light blue in color which indicates that the temperature is greater than the ambient outdoor temperature. On the other hand, the temperature contours for upward flow are predominantly dark blue which is nearly equal to the outside air temperature. One of the primary purposes of a ventilation system is to control temperature and thus from this view point the ventilation scheme in upward flow is better than that in downward flow. The temperature variations inside the poultry house occur due to heat produced by the hens because of their warm body temperatures. This process occurs via the thermal plumes generated by the hens. The airflow in Case 1 is from top to bottom and this direction opposes the naturally rising thermal plume. Due to this effect, the heat gets redistributed inside the poultry house and impairs the effectiveness of this ventilation scheme. On the other hand, in Case 2 the airflow is from bottom to top which is in the same direction as the naturally rising thermal plume. So in this scheme the thermal plume assists the airflow, heat is effectively carried out of the poultry house, and the temperature inside is maintained at a cooler level.

The present CFD simulations reveal that the cold and mild weather ventilation system in use in the United States, downward flow, for manure-belt cage hen houses is not effective from the view point of air quality and distribution. On the other hand, upward flow provides more effective ventilation in relation to diminishing disease spread. The ineffectiveness of the current system from an air quality viewpoint could be crucial if an outbreak of an airborne virus, for example avian influenza, were to occur. Upward flow is much better at containing contaminant and restricting spread. To support the CFD results, experimentation with an empty poultry house and a tracer gas such as sulfur hexafluoride $\left(\mathrm{SF}_{6}\right)$ should be done. There are optimizations needed to improve the practical application of the simple reversal of air flow depicted here. For example the upward flow case will be strengthened with an inlet system to more uniformly introduce fresh air to the hens, attic redesign to reduce the potential for condensation of moist warm exhaust air, and elimination of baffles at entry to the attic space. Also, an economic analysis with regard to financial implications of changing from the existing system to the new system needs to be done. 
Further studies could be done from the disease spread and containment point of view. Using data from virologists regarding the concentration of a particular airborne virus required to affect living beings and the life of such viruses, effective quarantine techniques could be developed. For this purpose the results of species diffusion can be used to find concentration in particular areas and appropriate quarantine measures can be taken. Using a similar approach, other poultry house architectures could also be investigated. One example of an alternative structure is the double envelope system wherein an interior wall with pores is installed inside the side walls. Air is moved from the building interior into the envelope through the pores, and passes through this envelope space to be exhausted at the top of the building. Also, other ventilation approaches such as the hot-weather wind-tunnel ventilation system could be analyzed using CFD.

\section{References}

[1] Economic Research service (ERS): http://www.ers.usda.gov/briefing/poultry/

[2] Jia, W.K., K. Parrish, C.R., and Naqi, S.A. A novel variant of avian infectious bronchitis virus resulting from recombination among three different strains. Archives of Virology, Vol. 140, No. 2, pp. 259-271, 1995.

[3] Mondal, S.P., Lucio-Martinez, B. Naqi, S.A., Isolation and characterization of a novel antigenic subtype of infectious bronchitis virus serotype DE072. Avian Dis., Vol. 45, No. 4, pp. 1054-1059, 2001.

[4] Gelb, J.J., Ladman, B.S., Tamayo, M. Gonzalez, M., Sivandandan, V., Novel infectious bronchitis virus S1 genotypes in Mexico 1998-1999. Avian Dis., Vol. 45, No. 4, pp. 1060-1063, 2001.

[5] Ford, B., Diaz, C., Hewitt, M. Passive downdraught cooling - architectural integration in Seville. PLEA Conference Proceedings: Architecture City, Environment, Cambridge: James \& James, 2000.

[6] Givoni, B., Passive and Low Energy Cooling of Buildings. 1994, New York: Van Nostrand Reinhold.

[7] Fathy, H., Natural Energy and Vernacular Architecture. 1986, Chicago: University of Chicago Press.

[8] Alvarez, S. Full scale experiments in EXPO '92 the bioclimatic rotunda. PLEA Ninth Conference Proceedings, Seville, Spain, 1991.

[9] FLUENT User's Guide, Ver. 6.0, Lebanon, N.H., Fluent Inc. 2005.

[10] GAMBIT User's Guide, Ver. 2.0, Lebanon, N.H., Fluent Inc. 2005.

[11] Lee I. B. and Short T. H. Verification of Computational Fluid Dynamic Temperature Simulations in a Full-Scale Naturally Ventilated Greenhouse. ASAE, October 2000.

[12] Sun H., Stowell R.R., Keener H.M., Michel Jr. F.C., Two-Dimensional CFD modeling of air velocity and ammonia distribution in high - rise hog building, Trans. ASAE, Vol. 45, No. 5, pp. 1559-1568, 2002.

[13] Lee I.B., You B.K., Choi K.H., Jeun J.G., Kim G.W., Study of internal climate for naturally and mechanically ventilated broiler houses, ASAE Paper No. 034060, St. Joseph, Mich, 2003. 
[14] Aerts J.M., Berckmans D., A virtual chicken for climate control design: Static and Dynamic simulations of heat losses, Trans. ASAE, Vol. 47. No. 5, pp. 1765-1772, 2004.

[15] Pawar, S. Air Quality and Ventilation Analysis of Poultry Houses using Computational Fluid Dynamics, M.S. Thesis, The Pennsylvania State University, Dept. of Mech. and Nuc. Engr., May 2006. 


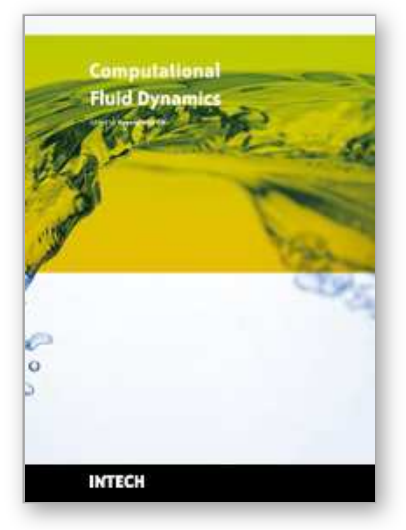

\section{Computational Fluid Dynamics \\ Edited by Hyoung Woo Oh}

ISBN 978-953-7619-59-6

Hard cover, 420 pages

Publisher InTech

Published online 01, January, 2010

Published in print edition January, 2010

This book is intended to serve as a reference text for advanced scientists and research engineers to solve a variety of fluid flow problems using computational fluid dynamics (CFD). Each chapter arises from a collection of research papers and discussions contributed by the practiced experts in the field of fluid mechanics. This material has encompassed a wide range of CFD applications concerning computational scheme, turbulence modeling and its simulation, multiphase flow modeling, unsteady-flow computation, and industrial applications of CFD.

\section{How to reference}

In order to correctly reference this scholarly work, feel free to copy and paste the following:

Sourabh R. Pawar, John M. Cimbala, Eileen F. Wheeler and Darla V. Lindberg (2010). Contaminant Dispersion Within and Around Poultry Houses Using Computational Fluid Dynamics, Computational Fluid Dynamics, Hyoung Woo Oh (Ed.), ISBN: 978-953-7619-59-6, InTech, Available from:

http://www.intechopen.com/books/computational-fluid-dynamics/contaminant-dispersion-within-and-aroundpoultry-houses-using-computational-fluid-dynamics

\section{INTECH}

open science | open minds

\section{InTech Europe}

University Campus STeP Ri

Slavka Krautzeka 83/A

51000 Rijeka, Croatia

Phone: +385 (51) 770447

Fax: +385 (51) 686166

www.intechopen.com

\section{InTech China}

Unit 405, Office Block, Hotel Equatorial Shanghai

No.65, Yan An Road (West), Shanghai, 200040, China

中国上海市延安西路65号上海国际贵都大饭店办公楼 405 单元

Phone: +86-21-62489820

Fax: $+86-21-62489821$ 
(C) 2010 The Author(s). Licensee IntechOpen. This chapter is distributed under the terms of the Creative Commons Attribution-NonCommercialShareAlike-3.0 License, which permits use, distribution and reproduction for non-commercial purposes, provided the original is properly cited and derivative works building on this content are distributed under the same license. 